\title{
Ultrastructural Assessment of the Integrity of the enteric Mucosa of Commercial Turkeys Vaccinated against Coccidiosis
}

\section{-Author(s)}

\section{Martins MRFB \\ Mendes AA" \\ Milbradt EL" \\ Almeida Paz ICL" \\ Martins BB" \\ Fernandes BCS"}

Biosciences Institute, São Paulo State University, Botucatu - Brazil

" School of Veterinary Medicine and Animal Science, São Paulo State University, Botucatu - Brazil

\section{Mail Address}

Corresponding author e-mail address Márcia Regina Fernandes Boaro Martins Rua: João Simões, no 157, Vila Padovan 18607-691. Botucatu, SP, Brazil

Phone: (5514) 3880-0040

Email: marcia@ibb.unesp.br

\section{-Keywords}

Bird, diseases, poultry production, protozoan parasites.

\section{ABSTRACT}

The objective of this study was evaluated the villus integrity of commercial turkeys submitted to coccidiosis prevention methods and challenged with Eimeria field oocysts, using scanning electron microscopy. Sixty BUT 9 female commercial turkeys were distributed in a completely randomized block design split with two treatments: T1control diet without vaccinations against coccidiosis and anticoccidial drug, and T2- vaccinated against coccidiosis (commercial vaccine). On d 21 of life, all birds of all treatments were challenged with a mixed-species containing E. meleagrimitis and E. galopavonis, via crop intubation with $1 \mathrm{~mL}$ of $\sim 20,000$ sporulated oocysts/bird. The size of the inoculum was determined in previous experiments. At 27 and 70 days of age, five birds per treatment were randomly removed to evaluate the intestinal integrity. Duodenum, jejunum and ileum segments were collected and processed according to routine scanning electron microscope. The enteric mucosa integrity of the commercial turkeys subjected to coccidiosis vaccination was reduced when compared to the birds of the control treatment. There was no difference in the performance results, therefore these results cannot be attributed to the vaccination as well as to the ineffectiveness against the challenge that was administered.

\section{INTRODUCTION}

The most relevant enteric diseases of infectious origin in turkeys are hemorrhagic enteritis, necrotic enteritis, histomoniasis, poult enteritis and mortality syndrome (PEMS), salmonellosis, and coccidiosis (Hafez, 2004; Hafez, 2013).

Coccidiosis or eimeriosisis caused by protozoan parasites of the genus Eimeria, and it is considered one of the most important diseases in the poultry industry. Eimeria not only causes enteritis and diarrhea, impairing the intestinal absorption of nutrients, but also has a synergistic effect with other diseases, which become more severe in the presence of coccidiosis (Allen \& Fetterer, 2002). Low infection levels of coccidia may reduce the birds'metabolic and immune efficiency, causing significant economic losses in the turkey industry (Lillehoj \& Lillehoj, 2000).

Disease prevention methods, associated with adequate management practices, are necessary to proper control and reduce disease outbreaks. When disinfection and cleaning alone are not sufficient to control the disease, anticoccidials need to be added to the feed or birds need to be vaccinated, because Eimerias poocysts remain viable for more than a year in the environment (Allen \& Fetterer, 2002). Live vaccines are still not frequently used in turkeys, particularly in commercial production. The economic impact, the production benefits, and the limitations of vaccination and control strategies of coccidiosis is improving over time (Allen \& Fetterer, 2002). 
Martins MRFB, Mendes AA, Milbradt EL, Almeida Paz ICL, Martins BB, Fernandes BCS

\section{Ultrastructural Assessment of the Integrity of the enteric Mucosa of Commercial Turkeys Vaccinated against Coccidiosis}

The objective of this study was to assess the integrity of the enteric mucosa of commercial turkeys vaccinated against coccidiosis and challenged with oocysts of a field species of Eimeria, using scanning electron microscopy.

\section{MATERIAL AND METHODS}

In this experiment, seventyone-day-old female commercial turkey poults (British United Turkeys - BUT Big 9) were housed in the experimental aviary of UNESP (São Paulo State University), Veterinary Medicine and Animal Science School (FMVZ), Botucatu, Brazil. The poults were vaccinated at the hatchery against Newcastle disease and infectious rhinotracheitis. All birds were submitted to the same housing, feed management, and daily management practices, according to the recommendations of the BUT manual [12].

The birds were distributed in a completely randomized block design into two treatments. In Treatment 1, birds were not vaccinated against coccidiosis, and in Treatment 2 , birds received a vaccine against coccidiosis (commercial vaccine, with a pool of oocysts of E. adenoeides, E. dispersa, E. meleagrimitis, and E. gallopavonis).

Birds were housed in experimental pens covered with sawdust litter. Birds were housed at densities of $21 \mathrm{birds} / \mathrm{m}^{2}$ in the first week, $9.8 \mathrm{birds} / \mathrm{m}^{2}$ between the second and sixth weeks, and $4.2 \mathrm{birds} / \mathrm{m}^{2}$ from the seventh week up to the slaughter age (BUT, 2013).

Water and feed were supplied ad libitum. The diets were iso-nutritious and the feeding program was divided into four phases: starter (0 to $3 \mathrm{wk}$ ), grower (4 to $6 \mathrm{wk}$ ), developer (7 to $8 \mathrm{wk}$ ), and finisher (9 to 10 wk). The experimental diets were formulated to meet or exceed the minimum nutritional requirements of turkeys of turkeys according to the NRC (1994).

On d 21, each bird of both treatments was challenged with $1 \mathrm{~mL}$ of a mixed-species inoculum containing $\sim 20,000$ sporulated oocysts of E. meleagrimitis and E. galopavonis. The concentration of the inoculum was determined in previous experiments, and it was administered directly into the esophagus of the birds, via gavage.

Ond 27 and $d$ 70, five birds per treatment were randomly selected, sacrificed, and necropsied to evaluate the integrity of the intestinal mucosa. The ileum, duodenum and jejunum were longitudinally opened, stretched, and washed with $0.1 \mathrm{M}$ phosphate buffer $(\mathrm{pH}$ 7.3) to remove the intestinal contents. Tissues were fixed in $2.5 \%$ glutaraldehyde in phosphate buffer $(\mathrm{pH} 7.3,0.1 \mathrm{M})$ for 24 hours at $4^{\circ} \mathrm{C}$. After fixation, the samples were rinsed in distilled water and fixed for 30 minutes in $0.5 \%$ osmium tetroxide in distilled water. The material was dehydrated in an ascending ethanol series (7.5\% to $100 \%)$ and then dried with liquid carbon dioxide in a Balzers CPD-020 critical point drying apparatus, assembled on "stubs", and metalized with $10 \mathrm{~nm}$ gold using a sputter coater Bal-Tec SCD 050.The samples were examined and photographed using a scanning electron microscope FEI Quanta 200 from 10 to $15 \mathrm{kV}$.

Each bird represented an experimental unit. The results were subjected to analysis of variance (ANOVA) and the means were compared by the t-test $(p<0.05)$, using the SAS statistical program (SAS, 2004).

The experimental protocol was approved by the Commission of Ethics in Research ( $n^{\circ} 188 / 2007$ CEEA) of the Universidade EstadualPaulista "Júlio de Mesquita Filho", Botucatu Campus, Brazil.

\section{RESULTS AND DISCUSSION}

The vaccinated turkeys were significantly heavier $(p<0.05)$ than those not vaccinated at slaughter age. In the initial stage (21 days) the mean weights were T1 (control) $=843 \mathrm{~g}( \pm 42 \mathrm{~g})$ and T2 (vaccination against coccidiosis $)=984 \mathrm{~g}( \pm 50 \mathrm{~g})$. The values obtained for transitional $(35 \mathrm{~d})$ were $T 1=1390 \mathrm{~g}( \pm 79 \mathrm{~g})$ and $\mathrm{T} 2=$ $1534 \mathrm{~g}( \pm 82 \mathrm{~g})$, for fattening (53 d) were $\mathrm{T} 1=3773 \mathrm{~g}$ $( \pm 148 \mathrm{~g})$ and $\mathrm{T} 2=3965 \mathrm{~g}( \pm 158 \mathrm{~g})$ and final stage (70 days) were $\mathrm{T} 1=5730 \mathrm{~g}( \pm 308 \mathrm{~g})$ and $\mathrm{T} 2=5870$ $\mathrm{g}( \pm 311 \mathrm{~g})$. During the growth phase (d 0-28), after coccidiosis challenge, only the birds belonging to the control group presented clinical signs of diseases such as diarrhea and prostration; there was no diseaseprovoked mortality.

Tests with the same commercial vaccine used in this study were previously conducted in commercial turkey flocks (Lee \& White, 2001; Clark \& Augustine, 2003; Linckersdorff-Sietz et al., 2004; Lee et al., 2006), and no typical clinical signs of "vaccine reaction" or significant impairment of live performance were reported. In chickens, according Peek \& Landman (2011), the best method for coccidiosis control in the field is the use of live attenuated vaccines, as these promote good protection and do not cause severe injury to the intestinal mucosa, which may happen with the use of live vaccines. However, there are no attenuated vaccines for turkeys. 
Martins MRFB, Mendes AA, Milbradt EL, Almeida Paz ICL, Martins BB, Fernandes BCS

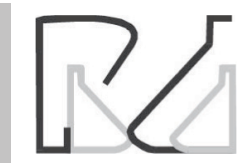

The enteric morphology evaluation in the growth phase (0-28d) confirmed better villus integrity in the duodenum, jejunum and ileum of the vaccinated birds (T2) compared with the same segments of the control birds (T1), indicating the protection of the intestinal cells provided by the vaccine against the injury caused by the coccidial challenge (Figure 1). According to Chapman et al. (2005), because live anti-coccidial vaccines are administered only once during the growout, re-infection, by ingesting small doses of vaccine oocysts from the feces or even from non-vaccine oocysts present in the litter, is essential for the establishment of immunity. The results of the present study indicate that the vaccinated birds made better use of the energy and of the chemical compounds, which besides ensuring adequate structural conditions of the mucosal cells of the digestive tract. They also ensured a better balance of the processes that determine the enteric mucosa turnover, resulting in a better absorption and digestion of the products.

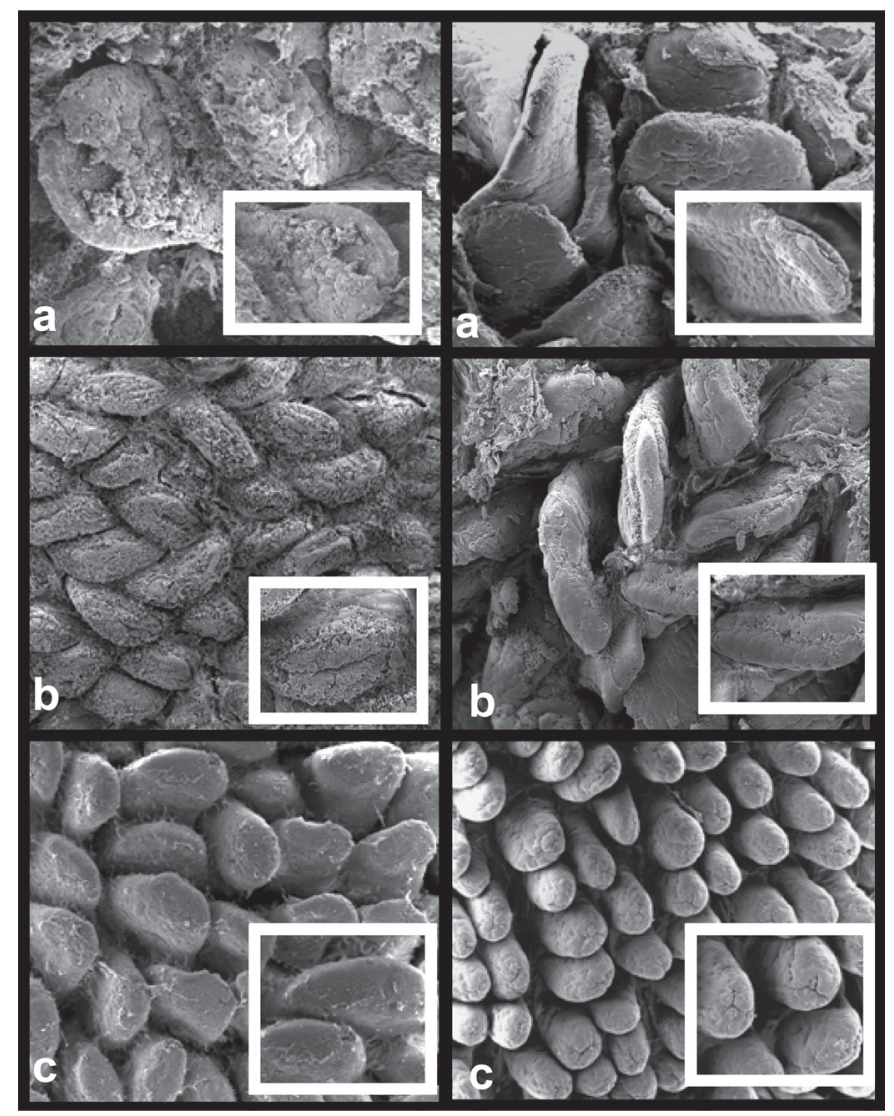

Figure 1 - Scanning electromyography of the mucosal of commercial turkeys in the initial breeding stage (27 days old). Left column - intestinal segments of birds subjected to the control diet without vaccination and without anticoccidial drugs. Right column birds subjected to vaccination. a) duodenal segment, b) jejunum and c) ileum. 200X.In set: 400X.

However, at slaughter age (70 days), the integrity of villi of the duodenum and jejunum of both vaccinated (T2) and non-vaccinated (T1) turkeys was compromised
Ultrastructural Assessment of the Integrity of the enteric Mucosa of Commercial Turkeys Vaccinated against Coccidiosis

(Figure 2). This result suggests that coccidial lesions preferentially affect the anterior segments of the small intestine, resulting instructural disorganization of the enteric mucosa cells and preventing villus turnover.

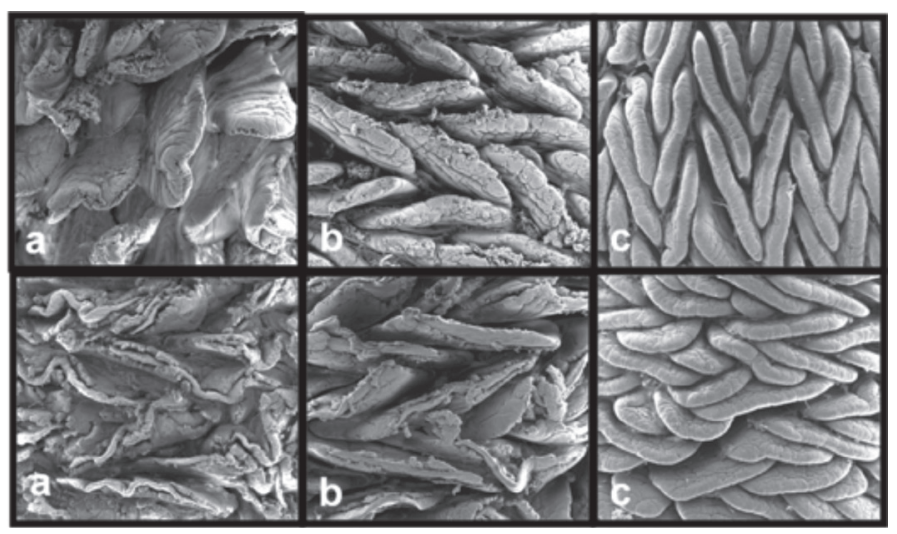

Figure $\mathbf{2}$ - Scanning electromyography of the mucosal of commercial turkeys in the final breeding stage (70 days old). 200X. In the first row, birds subjected to the control diet without vaccination and without anticoccidial drugs. Second row, birds subjected to vaccination against coccidiosis (commercial vaccine). a) duodenal segment, b) jejunum segment and c) ileum segment. 200X.

Irrespective of the treatments, changes in the shape and organization of the villi were observed at different ages. At $27 d$ of age, duodenal villi were dispersed and leaf-shaped, whereas the jejunum and the ileum presented high villus density and finger-shaped villi. At 70 days of age, duodenal villi were very similar to those observed at21 days of age, i.e., dispersed and leaf-shaped. On the other hand, the jejunum and the ileum presented high villus density, and tongue-shaped villi arranged in a zigzag manner (Figure 2). These observations are consistent with literature reports on the mucosa of broiler chickens (Yamauchi \& Isshiki, 1991; Pelicano et al., 2003; Van Leeuwen et al., 2004). According to those authors, the zigzag organization of the villi allows more efficient nutrient uptake when compared with randomly organized villi, since the distance traveled by the food bolus is higher in a zigzag flow, thereby enabling greater contact between the nutrients and the surface of the intestinal epithelium.

\section{CONCLUSION}

The vaccination used as a method to prevent and control coccidiosis preserved the intestinal morphology integrity of turkeys, besides proving to be efficient in the initial stage.

\section{ACKNOWLEDGMENTS}

We thank Mr. Alcides Carlos Lacerda and Marcos Alexandre Pavan for their technical support. FAPESP for financial support. 
Martins MRFB, Mendes AA,

Milbradt EL, Almeida Paz ICL,

Martins BB, Fernandes BCS

\section{REFERENCES}

Allen PC, Fetterer RH. Recent advances in biology of Eimeria species and diagnosis and control of infection with these coccidian parasites of poultry. Clinical Microbiology Reviews 2002;15:58-65.

British United Turkeys. Products [cited 2013 Set 10]. Available from: <http:// www.aviagenturkeys.com/us/products/but/but-6.aspx>.

Clark RS, Augustine P. Coccidiosis in Turkeys: disease. World Poultry Turkey Special 2003;14-17.

Chapman HD, Roberts B, Shirley MW. Guidelines for evaluating the efficacy and safety of live anticoccidial vaccines, and obtaining approval for their use in chickens and turkeys. Avian Pathology 2005;34:279-290.

Hafez HM. Overview on enteric diseases of turkeys and their economic impact. Proceedings of the 5th International Symposium on Turkey Diseases; 2004; Berlin. Germany. v.11, p.128-170.

Hafez HM. Enteric Diseases of Poultry with Special Attention to Clostridium perfringens. Pakistan Veterinary Journal 2011; 31(3):175-184.

LeeEH, Cosstick T, Sajnovic S. Drug-free turkey production [2013 Ago 11]. Canadian Poultry;2-3. Available:<http://www.vetechinc.com/ documents/content_33.pdf>. Access: 11/18/2013.

Lee $\mathrm{EH}$, White M. Vaccination to control coccidiosis in turkeys. Internacional Poultry Production 2001;9(5):35.

Linckersdorff-Sietz B, Gansinger D, Guillot I, Salisch H, Schwarzer C. First pratical experiences with Cocciv ac®-T in Germany. Proceedings of the 5th International Symposium on Turkey Diseases; 2004; Berlin. Germany. p. 279-296.

\section{Ultrastructural Assessment of the Integrity of the enteric Mucosa of Commercial Turkeys Vaccinated against Coccidiosis}

Lillehoj HS, Lillehoj EP.Avian coccidiosis.A review of acquired intestinal immunity and vaccination strategies.Avian Diseases 2000;44:408-425.

National Research Council. Nutrient requirements of poultry.8 ed. Washington: National Academy Press; 1984.

Peek HW, Landman WJM. Coccidiosis in poultry: anticoccidial products, vaccines and other prevention strategies. Reviewarticle. VeterinaryQuartely 2011;31(3):143-161.

Pelicano ERL, Souza PA, Souza HBA, Oba A, Norkus EA, KodawaraLM,Lima TMA. Morfometria e ultra-estrutura da mucosa intestinal de frangos de corte alimentados com dietas contendo diferentes probióticos. Revista Portuguesa de Ciências Veterinárias 2003;98:125-134.

SAS. Statistical Analysis System. SAS user'sguide: statistic. Cary: SAS Institute; 2004

Sun X, McElroy A, Webb Jr KE, Sefton AE, Novak C. Broiler performance and intestinal Alterations when Fed Drug-Free Diets. Poultry Science 2005;84:1294-1302.

Van Leeuwen P, Mouwen JM, Van der Klis JD, Verstegen MW. Morphology of de small intestinal mucosal surface of broilers in relation to age, diet formulation, small intestinal microflora and performance. British Poultry Science 2004;45:41-48.

Ziomko I, Karamon J, Cencek T, Gornowicz E, Ashash U. Prevention of broiler chick coccidiosis using the inactivated subunit vaccine Coxabic $®$. Bulletin Veterinary Institute Pulawy2005;49:299-302.

Yamauchi K, Isshiki Y. Scanning electron microscopic observations on the intestinal villi in growing white leghorn and broiler chickens from 1 to 30 days of age. British Poultry Science 1991;32(1):67-78. 